\title{
Design Educacional como Ferramenta no Processo de Construção de Material Didático Digital para Ensino de Pensamento Computacional
}

\author{
Educational Design as a Tool in the Process of Building Digital Didactic Material for \\ Teaching Computational Thinking
}

Ana Vitoria de Bacelar Machado e Silva (iD https://orcid.org/0000-0003-0469-2799

Universidade Federal do Pará (UFPA)

E-mail: av503vitoria@gmail.com

Gabryella Rocha Rodrigues Silva (iD https://orcid.org/0000-0003-2528-8138

Instituto Federal do Pará (IFPA)

E-mail: gabryella.rocha@gmail.com

Danielle Costa Carrara Couto (D) https://orcid.org/0000-0003-3810-1686

Universidade Federal do Pará (UFPA)

E-mail: danifc@ufpa.br

\section{Resumo}

Atualmente a necessidade de alunos compreenderem, utilizarem e criarem tecnologias digitais de forma crítica, passando de consumidores a construtores de novas soluções, é cada vez mais essencial para escolas de Ensino Básico. O projeto Manas Digitais tem como propósito fomentar em escolas públicas do $\mathrm{PA}$, a prática do pensamento computacional e contribuir com a equidade de gênero em carreiras de Tecnologia da Informação. Durante o período de confinamento da pandemia do COVID-19, o projeto propôs o uso de Design Educacional para apoiar a Educação a Distância e documentou um processo para criação de Material Didático Digital para difundir o ensino de Programação. O processo metodológico foi estruturado no modelo ADDIE e encontra-se em fase de desenvolvimento e avaliação por professores de cinco Escolas Públicas. Por fim, todos os templates e materiais didáticos serão publicados gratuitamente em site web, enfatizando também que áreas Tecnológicas são ambientes para todos, principalmente meninas e mulheres. O projeto desta maneira pretende contribuir com educadores que poderão reutilizar os modelos propostos em um momento em que muitos precisam se adaptar e reinventar-se.

Palavras-chave: Material Didático. Tecnologia Educacional. Programação.

\section{Abstract}

Currently students need to understand, use and create digital technologies in a critical way. Moving from consumers to builders of new solutions, is getting more essential to 
the elementary schools. The "Manas Digitais" project aims to promote in the public schools of the PA state, the practice of computational thinking and contribute to the gender equity in the Information Technology careers. During the period of COVID-19 pandemic confinement, the project proposed the use of Educational Design to support Distance Education and documented a process for creating Digital Didactical Material to disseminate the teaching of Programming. The methodological process was structured in the ADDIE model and is currently being developed and evaluated by teachers from five Public Schools. Finally all the templates and teaching materials will be published for free on a website, also emphasizing that Technological areas are environments for everyone, especially girls and women. The project thus intends to contribute with educators who will be able to reuse the proposed models at a time when many need to adapt and reinvent themselves.

Keywords: Courseware. Educational Technology. Programming.

\section{Introdução}

No Brasil, o currículo do ensino médio foi modificado e novas competências foram exigidas, com a introdução da nova Base Nacional Comum Curricular em 2017 (BNCC). Enquanto no passado, discutia-se o papel da tecnologia como ferramenta de ensino nas salas de aula, atualmente discute-se a integração do pensamento computacional ao currículo escolar.

O termo pensamento computacional foi descrito por Wing (2006), como sendo o processo cognitivo usado na resolução de problemas, fazendo uso de conceitos da ciência da computação, a fim de habilitar os estudantes a organizarem suas soluções a partir de habilidades como abstração, decomposição, depuração, automação, recursividade, iteração e entre outros.

Portanto, a partir da exigência da nova BNCC, observa-se a necessidade de se explorar novas competências com os alunos, a fim de compreenderem, utilizarem e criarem tecnologias digitais de forma crítica, passando de consumidores a construtores de novas soluções.

Porém, é notório que atividades ligadas à computação são pouco inseridas nas escolas brasileiras - principalmente públicas - em especial pela carência de recursos tecnológicos, como apresentado pelo Censo Escolar realizado pelo INEP (2019).

Sendo assim, emerge a necessidade do uso de métodos inovadores no processo de ensino-aprendizagem, que abordem esses conceitos de maneira acessível e que envolvam estratégias atrativas, sem a dependência do uso de hardware.

Portanto, para promover o desenvolvimento do pensamento computacional, baseado na resolução de um problema, de uma forma ativa, elevando o interesse e a motivação dos alunos pelos conteúdos das disciplinas, Bell, Witten e Fellows (2015) criaram a metodologia de Computação Desplugada, como forma de propor a disseminação de atividades lúdicas, que trabalham conceitos e técnicas específicas da computação, explorando a criatividade e o trabalho em equipe sem o uso de hardware e software.

Revista de Estudos e Pesquisas sobre Ensino Tecnológico, v.6, Edição Especial Desafios e avanços educacionais em tempos da COVID-19, 155920, 2020. 
Neste contexto nasce em 2018 o projeto Meninas Digitais de Ananindeua - Pará (mais conhecido como Manas Digitais), parceiro do Programa Meninas Digitais da Sociedade Brasileira de Computação (Maciel, Bim e Figueiredo, 2018) e contemplado pela chamada pública CNPQ/MCTIC N³1/2018 - Meninas nas Ciências Exatas, Engenharias e Computação, com o propósito de fomentar em escolas públicas da região metropolitana de Belém a prática do pensamento computacional e contribuir com a equidade de gênero nas carreiras de Ciência, Tecnologia, Engenharia e Matemática (STEM - Science, Technology, Engineering and Mathematics).

O projeto desenvolveu com os alunos do ensino fundamental e médio das escolas públicas atendidas, atividades práticas, minicursos e oficinas envolvendo o pensamento computacional, bem como a realização de eventos em instituições de ensino superior parceiras para a discussão e conscientização da importância feminina na área de computação (Silva et tal, 2019, 367). Além do planejamento da elaboração de um Material Didático Digital (MDD) que contempla os conteúdos abordados nas ações do projeto, e outros temas da ciência da computação.

Entretanto, a pandemia da COVID-19 pelo novo coronavírus (SARS-CoV-2), se apresentou como um dos maiores desafios para educação em escala global deste século. $\mathrm{E}$ o período de isolamento social para conter o vírus afetou também o desenvolvimento do projeto das Manas Digitais. Desde o dia 17 de março de 2020, o estado do Pará suspendeu as aulas na rede pública, como medida de combate à disseminação desse vírus, aliado ao isolamento social, o que limitou a circulação de pessoas nas ruas da capital e outras cidades como Ananindeua. As escolas públicas tiveram suas atividades presenciais paralisadas, o que impactou na continuação das intervenções presenciais planejadas pelo projeto até os dias atuais.

Entretanto, como medida de contenção, o MDD foi construído, conforme planejamento inicial do projeto, para dar continuidade de forma virtual às ações nas três instituições de ensino superior e cinco escolas públicas envolvidas. Os objetivos principais do MDD são: facilitar o acesso à informação das atividades desenvolvidas nas escolas com conteúdo disponibilizado em meio digital, e apresentar conceitos de programação de maneira lúdica e interessante, ressaltando a participação feminina na área e fomentando debates sobre questão de gênero nas Escolas.

Além da introdução, este trabalho expõe nas quatro primeiras seções o projeto das Manas Digitais, os conceitos de Educação a Distância, Design Educacional e modelo ADDIE; a quinta seção apresenta os trabalhos correlatos; a sexta seção descreve o processo de produção do MDD; a sétima seção aborda os resultados obtidos até o momento; e por fim, a oitava seção é relativa às considerações finais.

\section{Manas Digitais}

A programação computacional é uma ciência multidisciplinar que ajuda na resolução de problemas cotidianos e no desenvolvimento de raciocínio lógico. Em busca de acompanhar esse acelerado desenvolvimento tecnológico e incentivar a participação de mulheres nas áreas da STEM, surge um projeto colaborativo entre três grandes universidades da região norte do Brasil - Universidade Federal do Pará, Instituto Federal do Pará e Universidade da Amazônia - as Manas Digitais.

Revista de Estudos e Pesquisas sobre Ensino Tecnológico, v.6, Edição Especial Desafios e avanços educacionais em tempos da COVID-19, 155920, 2020. 
Apesar de o projeto ser voltado para o público feminino, as atividades foram realizadas com estudantes do ensino fundamental e médio, envolvendo ambos os gêneros nas Escolas Públicas. Essa conduta é adotada para facilitar a aceitação do trabalho por parte das escolas, e evitar qualquer tipo de segregação imprópria em um ambiente educacional. Apesar do envolvimento de meninos e meninas, todo o material utilizado nas atividades enfatiza à importância da presença feminina na área de Computação/TIC por meio de exemplos, ilustrações e menção aos grandes nomes femininos da área.

O projeto também desenvolve uma rede colaborativa que conta com a presença de mulheres profissionais na área de STEM da Região Norte e depoimentos em vídeo de figuras femininas que atuam em diferentes ramos da computação a fim de promover encontros entre profissionais e estudantes. Essas profissionais compartilham com a(o)s aluna(o)s suas experiências, desafios e oportunidades na carreira em TIC.

\section{Educação a Distância (EAD)}

A EAD, de acordo com Filatro (2018), é a troca de aprendizados entre indivíduos que não estão no mesmo ambiente físico e tem sua origem antes mesmo da era digital. Porém, muito mais que isso, um sistema EAD na sociedade atual representa uma demanda constante por técnicas inovadoras de ensino, que possam ser acessíveis, com metodologias atrativas e de fácil aprendizado.

Além disso, como posto por Moore e Kearsley (2007) busca-se atender diversas necessidades quando discursamos e utilizamos EAD, como: nivelar diferenças etária; atualizar expertises; aumentar aptidões em áreas da educação; adequar-se às necessidades dos usuários; redução de custos no ensino; direcionar projetos educacionais para públicos específicos; apoiar a qualidade dos sistemas educacionais que já existem; e proporcionar mais acesso a novos aprendizados.

E no contexto da pandemia do COVID-19, segundo Grandisoli, Jacob e Queiroz (2020) cerca de 48 milhões de estudantes deixaram de frequentar as atividades presenciais nas mais de 180 mil escolas de ensino básico espalhadas pelo Brasil, devido à necessidade de distanciamento social, como medida de segurança. Sendo assim, diversos alunos e professores tiveram que se adaptar à nova realidade, e buscar por novos meios de ensino-aprendizagem. Com isso, os conteúdos digitais adequam-se perfeitamente com o contexto atual, pois representam subsídios educacionais que podem ser postos em vários tipos de mídias, e apresentados através de novas tecnologias, como a digital e a mobile.

Embora a modalidade de EAD envolva os processos de ensino e de aprendizagem a distância, ela mantém também uma preocupação em articular conteúdos, objetivos e a iniciativa do aluno, como deve acontecer em qualquer processo pedagógico (Pereira et al, 2017, p. 39). Assim, é notório a necessidade de se utilizar processos, metodologias e ferramentas na construção de um projeto para EAD, fomentando a facilidade ao acesso à informação, e que se planejado, pode tornar-se um ambiente adequado para o aprendizado em diversas áreas de conhecimento.

\section{Design Educacional (DE)}

O DE é a concepção de uma solução educativa que, principalmente na atualidade, busca sair da linha do ensino tradicional aluno/professor. Para Filatro e Cairo (2017), é um conceito que, a partir de um processo bem definido, busca organizar a resolução

Revista de Estudos e Pesquisas sobre Ensino Tecnológico, v.6, Edição Especial Desafios e avanços educacionais em tempos da COVID-19, 155920, 2020. 
de um problema identificado, gerando uma abordagem que abrange todos os pontos chaves do projeto.

Segundo Batista (2008), Filatro e Cairo (2017), e Bates (2016), acredita-se que foi durante a Segunda Guerra Mundial que surgiu a primeira manifestação de DE, ao perceber-se a necessidade em treinar milhares de soldados. Para isso, o governo norte-americano juntou educadores e psicólogos para que materiais didáticos fossem desenvolvidos. Então, com base nos sucessos cinematográficos da época, os pesquisadores criaram filmes explicativos para o treinamento desses militares. $\mathrm{E} a$ partir deste evento, o DE se instaurou como um campo de planejamento educacional, em especial considerando o uso de materiais pedagógicos.

Filatro (2008) coloca DE como uma integração entre Ciências Humanas, Ciências da Informação e Ciências da Administração, e reafirma que essa rica relação traz diversas perspectivas e ensinamentos sobre aprendizado e como o ser humano comporta-se. E a partir dessa grande quantidade de conceitos atrelados ao DE, devemos escolher os que melhor encaixam-se ao projeto que está sendo desenvolvido, definindo objetivos e estratégias que influenciarão no sucesso do planejamento. Assim, o uso do DE como ferramenta chave permite abranger todos os pontos cruciais de uma solução educacional, já que parte de necessidades de aprendizagem, organizando e planejando o processo de criação de um sistema que possa atender tais necessidades e objetivos.

Brown e Green (2016) comentam que o DE pode ser sintetizado em três partes principais que são: Ter uma análise da situação para estipular quais instruções são necessárias e qual o passo-a-passou para chegar a essas instruções; produzir e por em prática o DE; e avaliar os resultados dessa implementação a partir do DE. Nesse sentido, uma das bases teóricas mais comum que caracteriza o DE e que exemplifica esse passo-a-passo - tomando como base a estratégia de organização de Filatro e Cairo (2017) - é formada por um conjunto de cinco etapas, chamadas de ADDIE: Análise, Design, Desenvolvimento, Implementação e Avaliação (do inglês Analysis, Design, Development, Implementation, and Evaluation).

Esse modelo de organização vem sendo empregado por instituições de ensino, principalmente no contexto de expansão do EAD. Bates (2016) pontua que universidade como U. K. Open University e Universidade Aberta dos Países Baixos, Thompson Rivers Open University e Athabasca University no Canadá, têm e ainda utilizam o ADDIE no planejamento de design de cursos EAD multimídia complexos.

À medida que os cursos de educação a distância se desenvolveram como cursos à distância online, o modelo ADDIE continuou e é ainda hoje utilizado por designers instrucionais em muitas instituições para redesenhar grandes aulas expositivas, ensino híbrido e cursos online completos. (Bates, 2016, p. 161).

O método ADDIE apresenta-se como o escolhido para este trabalho já que, além de englobar todas as etapas necessárias para o desenvolvimento de um projeto, é ideal para a aplicabilidade dessa característica recursiva, onde podemos trabalhar os estágios de cada etapa de maneira organizada, e inclusive realizar modificações e refinamentos contundentes (Batista, 2008, p.155).

\section{Método ADDIE}

Revista de Estudos e Pesquisas sobre Ensino Tecnológico, v.6, Edição Especial Desafios e avanços educacionais em tempos da COVID-19, 155920, 2020. 
Como posto por Bates (2016), as vantagens deste método são: qualidade do design; definição clara de objetivos de ensino-aprendizagem; estruturação minuciosa do conteúdo; mídias integradas; atividades e avaliações importantes que estão relacionadas com os resultados de ensino-aprendizagem esperados. Além disso o ADDIE é um modelo que identifica claramente os conceitos de Design Educacional de maneira detalhada, permitindo a criação de cursos de qualidade, baseados em um desenvolvimento com boas práticas de gerenciamento. Suas etapas são ilustradas na Figura 1.

Figura 1 - Método ADDIE.

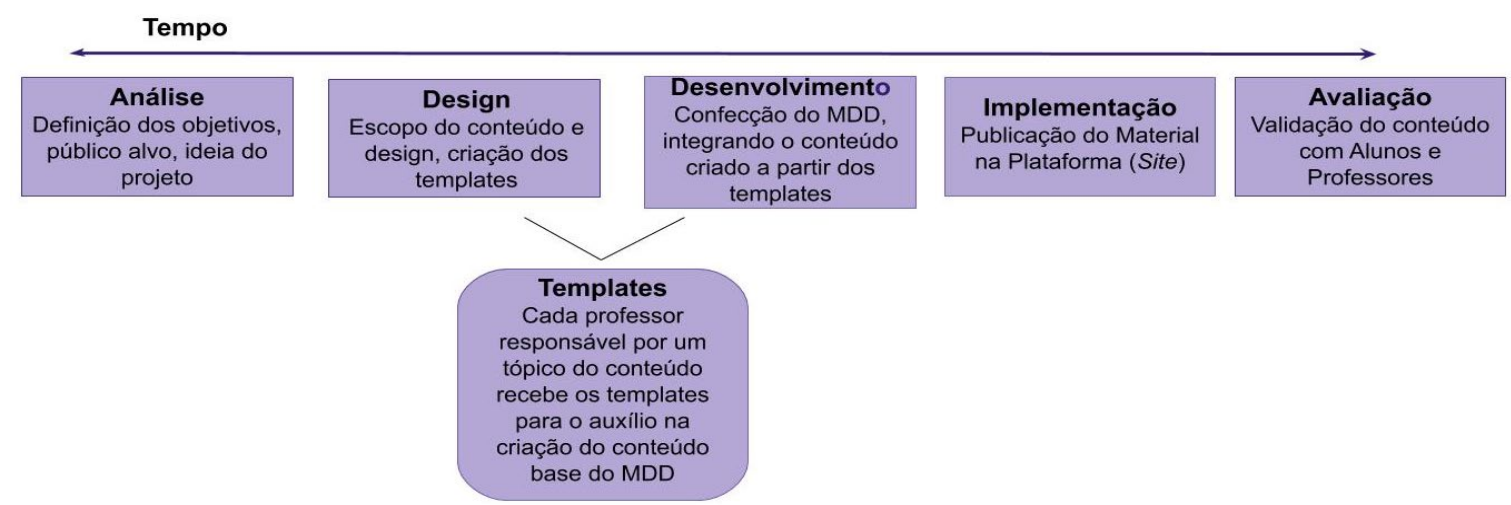

Fonte: Adaptado de Filatro e Cairo (2017)

Análise: onde identifica-se a necessidade educacional e, a partir do perfil do públicoalvo que fora especificado, idealizamos soluções plausíveis, definimos objetivos e caracterizamos os possíveis empecilhos, como limitações da plataforma escolhida ou mudança nas metas estabelecidas. Ainda em relação ao público-alvo e sua importância na fase de análise, quanto mais precisa for a caracterização do públicoalvo, mais subsídios estarão disponíveis para inspirar a retórica instrucional a ser desenvolvida nas atividades de autoria e roteirização, e decisões relativas ao design gráfico ou digital na atividade de produção de mídias. Sendo assim, com a etapa de análise bem defina, podemos esperar uma maior chance de sucesso em relação aos objetivos definidos.

Design: fase em que o projeto começa a ser estruturado de fato, pois são definidos: o escopo do conteúdo; templates; uma sequência para o material; as estratégias de abordagem; definição de objetivos específicos; ferramentas essenciais para a construção do material e quais plataformas serão utilizadas. Bates (2016) ainda relaciona a fase de design diretamente com os objetivos, pontuado que eles também podem ser definidos nessa fase.

Desenvolvimento: é quando realmente se percebe que o planejamento foi feito corretamente e as ideias se tornam hábeis para o desenvolvimento, ou pelo uso de novos elementos, ou pela adaptação de elementos que já existentes. Sendo assim, como posto por Filatro e Cairo (2017) é a etapa em que os materiais começam a ser confeccionado e - dependendo dos conceitos e ferramentas determinadas - as imagens são confeccionadas, ilustrações criadas, tipografia idealizada, animações são desenvolvidas, e qualquer outro tipo de material audiovisual ligado ao projeto é posto em prática.

Implementação: onde os materiais são disponibilizados na plataforma escolhida e divulgados em algum meio, como redes sociais e/ou fanpages. Importante ressaltar

Revista de Estudos e Pesquisas sobre Ensino Tecnológico, v.6, Edição Especial Desafios e avanços educacionais em tempos da COVID-19, 155920, 2020 
que os participantes do projeto já devem ter revisado, tanto o MDD, quanto a plataforma que irá hospedá-lo.

Avaliação: fase para verificar se os objetivos de aprendizagem determinados anteriormente foram absorvidos pelo público. A avaliação pode ser feita de diversas maneiras, através de formulários, checklist, questões avaliativas somativas no fim do processo ou até testes aplicados antes do uso do material. Essa fase compreende ainda o feedback e dados coletados a fim de identificar as áreas que necessitam de melhorias. Esses dados alimentam mudanças no design, desenvolvimento e implementação da próxima fase do curso (Bates, 160 p. 2016).

\section{Trabalhos Correlatos}

Com a caracterização de EAD, DE, aprendizado e tecnologias, as obras de Bates (2016), Batista (2008), Brown e Green (2016), Moore e Kearsley (2007), e Pereira et al. (2017) foram de extrema importância, para a contextualização e a estruturação deste projeto. Porém, as obras de Filatro (2018), Filatro (2008) e Filatro e Cairo (2017) serviram como base principal na formulação do MDD, a fim de evidenciar os métodos de organização e as etapas bem definidas do modelo ADDIE, e quanto o funcionamento do processo de criação de MDD no contexto de EAD.

\section{Material Didático para o ensino das Cinco Emoções Básicas}

O trabalho de Almeida (2017) foi focado principalmente no design de um material didático - para crianças entre 8 e 11 anos - que através de um conceito lúdico e divertido, aborda o ensino-aprendizagem das cinco emoções básicas (tristeza, alegria, nojo, raiva e medo). Utilizando os conceitos de design social, inovação social e Design Thinking $(D T)$, esse projeto, além de buscar desenvolver a empatia, procurou aperfeiçoar as relações interpessoais entre as crianças.

A autora apresentou de maneira detalhada a confecção do material, desde idealização, conteúdo, identidade visual e os protótipos, até resultar na versão final. Os materiais didáticos possuem tanto a versão do aluno quanto do docente e foram planejados para serem disponibilizados em um website.

\section{Design Educacional: Criação e Implementação de Capacitação Continuada a Distância para Professores da Rede Estadual de Educação Básica da Paraíba}

Conceituando EAD e DE, Figueiredo (2017) relaciona os dois termos e detalha o processo de criação de um curso de capacitação a distância para professores. A autora usa o modelo ADDIE como ferramenta base e descreve, inclusive, o desenvolvimento de mídias e a plataforma escolhida para a hospedagem dos conteúdos e aulas. Ademais, ela propôs que a validação do curso seja feita por profissionais especializados em didáticas educacionais e EAD, além de um questionário com questões de múltipla escolha.

\section{Desenvolvimento de uma Unidade Instrucional para Ensinar o Desenvolvimento de Apps No Ensino Fundamental com o App Inventor}

Filho (2019) buscou, através dos conceitos de DE e utilizando o método ADDIE, realizar o ensino de assuntos relacionados à computação utilizando a ferramenta App Inventor no Ensino Fundamental de escolas públicas brasileiras. O público-alvo são

Revista de Estudos e Pesquisas sobre Ensino Tecnológico, v.6, Edição Especial Desafios e avanços educacionais em tempos da COVID-19, 155920, 2020. 
professores que, mesmo que possuam alguma formação relacionada à tecnologia na educação, não tenham contato com os conhecimentos de computação.

Ademais, o curso é dividido em duas versões: uma curta, com o tema desenvolvimento e consumo sustentável; e uma longa, que detalha os conceitos e processos do desenvolvimento de Apps. O projeto foi aplicado duas vezes na escola selecionada pelos autores, e resultou em avaliações positivas mostrando aumento de aprendizado, além de análises contundentes sobre a diferença de resultados entre a versão curta e longa, e como o tempo afeta o processo de aprendizado dos alunos.

\section{Mobile Learning e Educação Corporativa}

Abordando métodos inovadores, Becker (2019) correlaciona em seu trabalho os conceitos de DE, e-learning e mobile learning, objetivando utilizar aplicativos móveis na educação híbrida para ambiente corporativo. A autora realizou um apanhado de diversos termos de aprendizado e pontuou como o sistema tradicional de ensino reinventa-se a partir de novas tecnologias.

Ela apresentou ainda os modelos tradicionais presenciais, nas salas de aulas; EAD tradicional, por correspondência, rádio, revistas e televisão; E-Learning, com um ponto de acesso fixo de internet, usando um computador; M-Learning, com uso de dispositivos móveis; e U-Learning, como aprendizado que utiliza sensores, móveis, tecnologias sem fio. Além disso, descreveu a importância do DE na criação dos métodos de aprendizado e como o modelo ADDIE caracteriza-se neste cenário.

\section{Estudo Sobre a Produção Científica Brasileira em Relação ao Tema de DE e EAD}

Dois artigos escolhidos focaram nessa temática. Pardim (2018) realizou uma busca e análise de mais de 126 trabalhos acadêmicos relacionados ao tema de DE e apresenta diversos autores conceituados na área. Além disso, descreve as principais característica e EAD e DE, e detalha como o método ADDIE funciona e quais suas principais etapas. O artigo também mostra gráfico com a relação de trabalhos publicados de acordo com as regiões brasileiras, e ano da publicação.

\section{Metodologia para Produção do MDD}

O MDD foi planejado para que também possa ser utilizado na forma impressa, atendendo principalmente as escolas públicas que têm carência em infraestrutura no Pará. Atualmente, o material encontra-se em fase de desenvolvimento, tendo sua fundamentação teórica já estabelecida e seu escopo bem definido. Como mencionado anteriormente, a projeto segue os conceitos de DE, utilizando o ADDIE como modelo organizacional, de acordo com as seguintes fases descritas por Filatro e Cairo (2017).

\section{Análise}

Nesta etapa que a problemática, solução, e objetivos - já mencionados anteriormente - foram definidos e, a partir disso, as características e detalhes do MDD foram estipulados. Como os conteúdos do material didático estão sendo elaborados de acordo com os principais assuntos abordados pelas Manas Digitais, a determinação do público-alvo segue a mesma linha do projeto, ou seja, aluno(a)s na faixa etária de

Revista de Estudos e Pesquisas sobre Ensino Tecnológico, v.6, Edição Especial Desafios e avanços educacionais em tempos da COVID-19, 155920, 2020. 
9 a 17 anos e professore(a)s, principalmente, de disciplinas das STEM nas escolas atendidas, entre elas: Química, Matemática e Ciências da Natureza.

Neste sentido, o perfil dos alunos é caracterizado por indivíduos que: possuem ou não conhecimento prévio em informática; alunos entre os níveis fundamental e médio, tanto do ensino público quanto particular; e alunos que foram ou não em busca de um MDD como principal fonte de aprendizado. Em relação ao perfil dos educadores, estão docentes que estão familiarizados ou não com o uso da tecnologia em sala de aula, e buscam adquirir conhecimentos relacionados à computação - para aplicação em sala de aula - ou professores que já fazem uso de recursos tecnológicos, mas desejam expandir suas expertises.

A partir do público-alvo definido, foram estipulados os módulos que compõe o MDD e que, como mencionado anteriormente, estão diretamente ligados com as ações realizadas pelo projeto Manas Digitais, os quais são: Computação Desplugada, onde são apresentados os conceitos iniciais de pensamento computacional especificamente sobre o que é um algoritmo e como ele funciona - porém sem o uso de computador; Criação de Aplicativos Android com App inventor, em que a programação em blocos apresenta-se de maneira adequada para a introdução ao mundo da programação mobile; Introdução à Programação com Python, já apresentando uma linguagem de programação e adentrando aos conceitos de desenvolvimento web na prática; e Design Thinking (DT) e a Construção de Soluções Inovadoras que ensina como usar os conceitos de DT para a criação de projetos tecnológicos que possam abranger problemas da realidade dos alunos.

Nesse contexto, um dos pontos-chave do MDD é o uso de conteúdos que estimulem a criatividade e a participação dos alunos, contendo diversos elementos visuais como imagens, ilustrações, histórias em quadrinho e vídeos narrados, tudo seguindo um roteiro planejado. A ideia é que um mesmo modelo de produção de MDD seja aplicado para os diferentes módulos do projeto (Computação Desplugada, Criação de Aplicativos Android com App inventor, Introdução à Programação com Python e DT e a Construção de Soluções Inovadoras).

Cada módulo terá vídeos de curta duração - que serão narrados e compostos por ilustrações - de tópicos do MDD, como por exemplo, atividades e curiosidades sobre o assunto. Além disso, a confecção do site onde será publicado todos os MDDs também terá o seu desenvolvimento documentado para que possa ser disponibilizado e um tutorial apresentado como forma de explicar a construção de um site baseado em DE.

Outro ponto importante é que cada módulo será desenvolvido pelas alunas de graduação vinculadas ao projeto, que estiveram diretamente ligadas com as aplicações das atividades relacionadas às ações das Manas Digitais. Porém, todos os conteúdos desenvolvidos serão avaliados pelas educadoras responsáveis pelo projeto, além dos professores das Escolas, para que o valor pedagógico do conteúdo seja validado.

\section{Design}

Depois de analisado o público-alvo e os objetivos a serem definidos, fora estimado a ordem do processo de criação em que, de maneira geral, tem-se: a) criação de um template (modelo) base com os tópicos e ordem dos conteúdos de cada módulo; b)

Revista de Estudos e Pesquisas sobre Ensino Tecnológico, v.6, Edição Especial Desafios e avanços educacionais em tempos da COVID-19, 155920, 2020. 
preenchimento dos templates; c) avaliação dos template pelas educadoras vinculadas ao projeto; d) redefinição dos templates com base nas avaliações; e) desenvolvimento do material didático, tendo os conteúdos do templates integrados em sua composição; f) desenvolvimento do protótipo interativo do site; g) validação do protótipo iterativo do site pelas educadoras; $h$ ) implementação do site na plataforma escolhida, com base no protótipo; i) publicação dos MDDs no site.

Para a confecção do design do MDD, as ferramentas principais que estão sendo utilizadas são: a) Adobe Photoshop, ideal para pintura digital e edição de imagens; b) Adobe Illustrator, para ilustrações, e outros elementos que sejam favorecidos pela vetorização característica do programa; c) website Canvas, para composição simples de imagem e uso de outros elementos gratuitos; d) Adobe InDesign, para a tipografia e montagem do material didático; e) Adobe XD, para a prototipagem do site, que ainda permite que uma cópia iterativa esteja disponível em nuvem; e) Adobe Premiere, responsável pela edição de vídeos; e f) Google Sites (https://sites.google.com) como plataforma principal do site do projeto, onde o material será armazenado.

Para a gestão da escala de cores, está sendo feito o uso do website Adobe Color (https://color.adobe.com), uma ferramenta gratuita que permite a criação de uma cartela de cores - dependendo da especificação desejada - a partir de uma ou mais cores bases. E para o design tipográfico, o Google Fontes (https://fonts.google.com), que disponibiliza gratuitamente diversas fontes com identidades visuais variadas.

Além disso, como o conteúdo é ligado às Manas Digitais, a identidade visual definida tem como protagonista a Maninha, personificação da logo oficial do projeto, já divulgada em artes postadas nas redes sociais que sofrerá adaptação aos diferentes módulos (Figura 2):

- Módulo de Computação Desplugada: tem como cores bases tons de roxo e como cores secundárias tons de amarelo. O tema idealizado é composto pela protagonista em contexto do dia a dia, em afazeres que podem não estar relacionados com computação diretamente.

- Módulo Criação de Aplicativos Android com App inventor: tem como cor base tons de roxo e como cores secundárias tons de verde. O tema idealizado é composto pela protagonista em contextos de videogames antigos, mais precisamente no estilo "64 bits".

- Módulo de Introdução a Programação com Python: tem como cor base tons de roxo e como cores secundárias tons de azul. O tema idealizado é composto pela protagonista como super-heroína interagindo com outros personagens e em posições de combate.

- Módulo de Design Thinking: tem como cor base tons de roxo e como cores secundárias tons de rosa, amarelo, verde e azul. O tema idealizado é "profissões", onde a protagonista é representada atuando em diversas profissões. 
Figura 2 - Identidade visual do Instagram das Manas Digitais
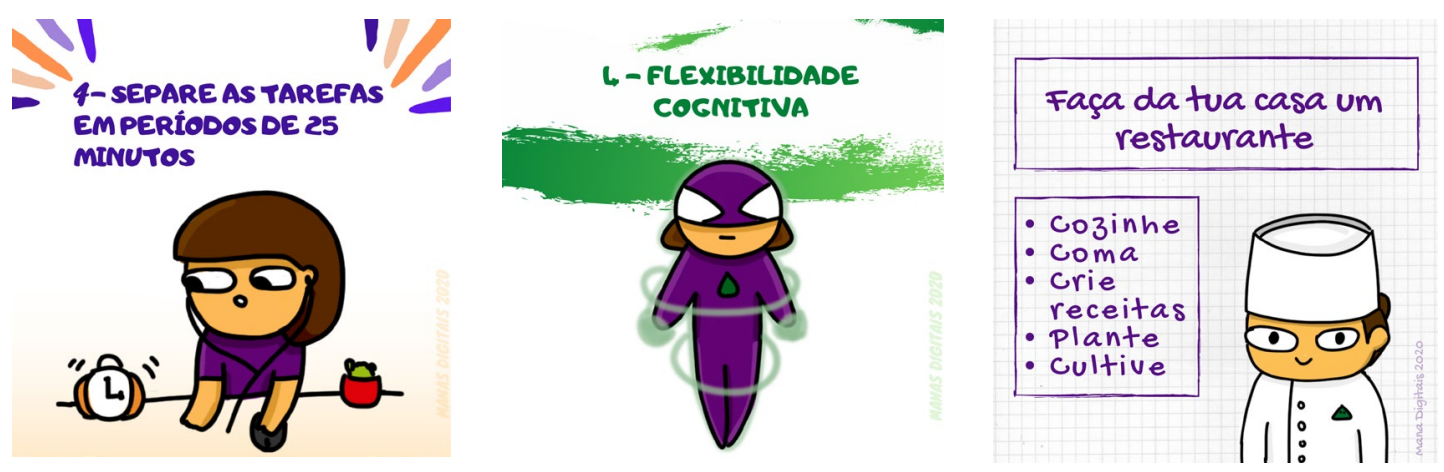

Fontes: Elaborado pelas autoras.

Os webcomics (histórias em quadrinho online) divulgados nas redes sociais das Manas Digitais falam sobre a área de TI e apresentam personalidades influentes na área e desempenham um papel importante na divulgação do projeto. As ilustrações são ricas em elementos que exaltam a identidade cultural da região amazônica artística e linguística - de maneira que os MDDs seguem as mesmas características.

Apesar da quantidade de cores propostas, a identidade visual está focada principalmente em tons de roxo - cor predominante presente na logo das Manas Digitais - que, além de referenciar o açaí (fruta típica da região), faz com que, inconscientemente, os MDDs sempre sejam uma referência ao projeto e à mensagem de criatividade que elas desejam passar à sociedade.

Como o público-alvo é misto, conceituamos dois modelos (denominado como templates) de cada um dos módulos, ou seja, uma versão para o aluno e uma para o docente, que possuem os detalhes sobre as atividades e como usar o MDD em sua plenitude. Para todos os módulos, os templates servem como guia de como é o escopo do material e qual a ordem das informações.

a) Template "Versão do Aluno": formado por três módulos principais - Introdução ao assunto, Atividades e Reflexões - e que possui campo para duas atividades. Além de um espaço de "Personalidades" em que são apresentados exemplos de mulheres influentes na área de tecnologia, e um tópico extra chamado "Curiosidades" a ser preenchido com curiosidades pertinentes sobre o tema abordado (Figura 3). 
Figura 3 - Exemplo dos tópicos presentes no Template do Aluno.
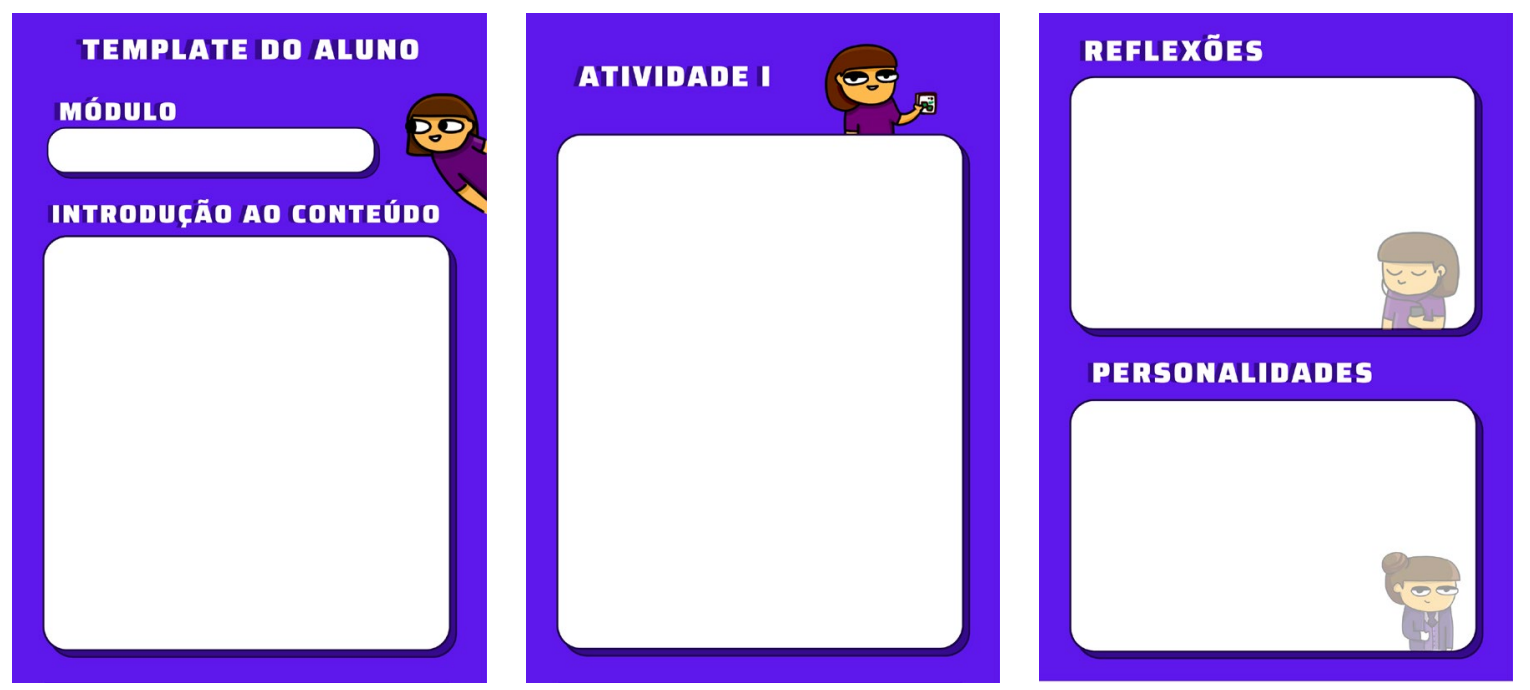

Fonte: Elaborado pelas autoras.

b) Template "Versão do Docente": formado por três partes principais - Introdução ao assunto; como aplicar as atividades e Reflexões com os alunos. Além disso, possui um espaço de "Dicas" que pode conter sugestão de sites e livros sobre o tema. Por fim, "Outras Dinâmicas" que pode ser usado para inserir mais exemplos de atividades simples sugeridas pelos professores do projeto (Figura 4).

Figura 4 - Exemplo dos tópicos presentes no Template do Docente.
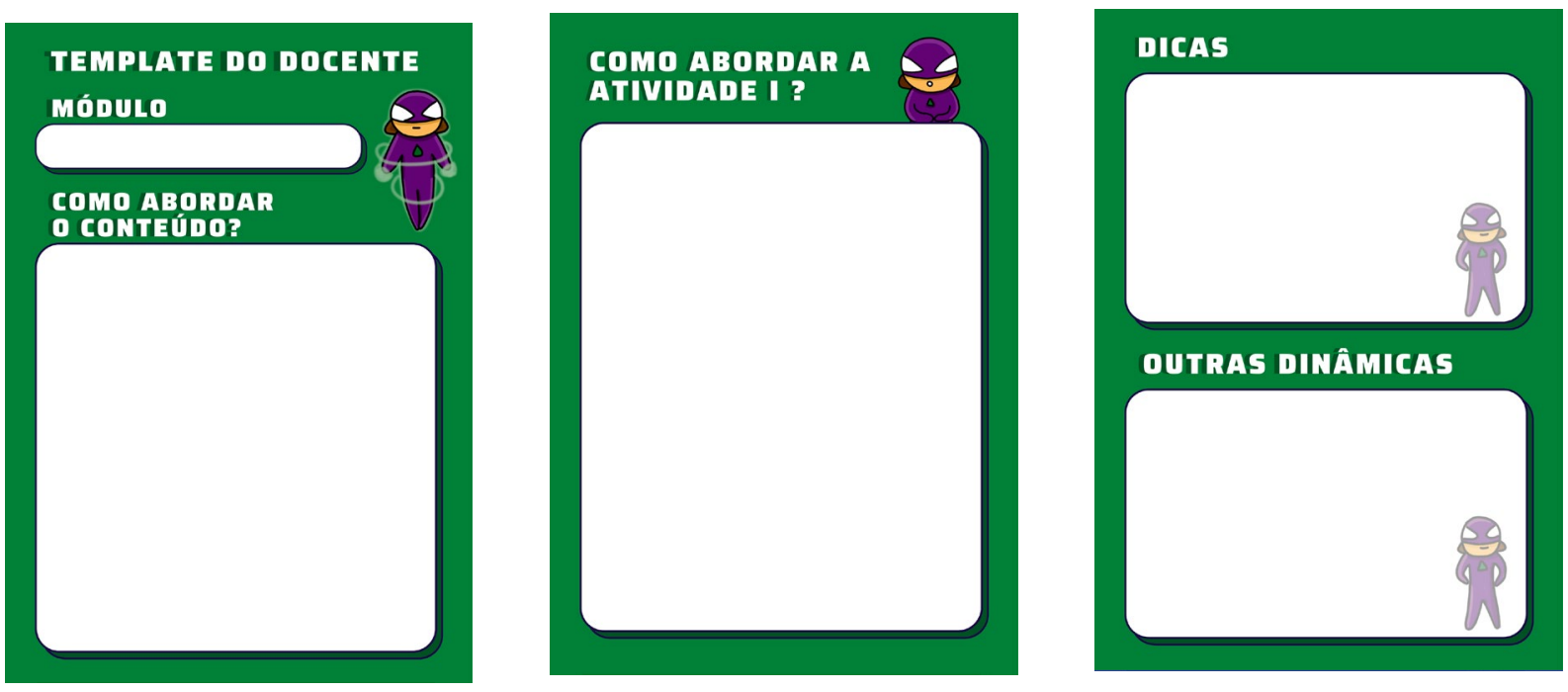

Fonte: Elaborado pelas autoras.

Com estes templates, já é possível que as partes envolvidas comecem a sintetizar os conteúdos, mesmo que o modelo final não esteja concluído. Depois de preenchidos na fase de desenvolvimento - e enviados para as educadoras responsáveis para avaliação prática do MDD, eles poderão ser corrigidos ou melhorados.

\section{Desenvolvimento}

Para a confecção dos MDDs, o primeiro passo é preencher os templates criados na fase de design de forma a contemplar todos os módulos (Computação Desplugada, App Inventor, Introdução à Programação com Python e Design Thinking). Além disso, desenvolver o modelo em si e sua tipografia, inserindo os conteúdos já revisados pelos 
professores. Essa é a etapa em que o projeto se encontra atualmente, onde os templates estão sendo preenchidos e outros elementos audiovisuais estão em processo de produção.

O website das Manas Digitais também está em fase de implementação e faz uso da plataforma Google Sites (https://sites.google.com). Tem suas sessões divididas em: a) "Início", onde temos a explicação do site e notícias diversas relacionadas ao projeto; b) "Materiais", onde serão apresentados os vídeos e as histórias de grandes mulheres da tecnologia além dos MDDs produzidos, de acordo com sistema de cores - para leitura digital - RGB (do inglês Red, Green, and Blue) e na versão para impressão em CMYK (do inglês Cyan, Magenta, Yellow, and Black); c) "Artigos" contendo publicações feitas pelas Manas Digitais; d) Oficinas e eventos futuros ou realizados; e por fim, a sessão e) "Sobre", a qual descreve como o trabalho das Manas Digitais é desenvolvido e seus integrantes.

O protótipo interativo de telas do site está sendo desenvolvido através do adobe XD, e será disponibilizado de forma interativa na sessão "Material Didático Digital". O site tem a predominância de tons de roxo e verde, cores que remetem a criatividade (imaginativo/sábio) e ser pacífico (crescimento saudável) segundo o Color Emotion Guide (2020), e que são semelhantes à identidade visual característica do projeto e contendo elementos regionais como o açaí e artes Marajoaras.

\section{Implementação}

Os MDDs assim como o website estão sendo desenvolvidos com os mesmos conceitos de $\mathrm{DE}$, e antes da divulgação serão testados pelos professores e alunos que participam do projeto, a fim de realizar melhorias para o lançamento final na web.

\section{Avaliação}

A avaliação do projeto será composta pelo processo de validação dos MDDs de acordo com proposto por Filho (2019). Com a participação das turmas de Escolas Públicas ligadas às ações das Manas Digitais. Também ocorrerá uma dinâmica, usando o material do módulo de DT, apenas com as alunas bolsistas de Iniciação Científica Júnior (total de 15 meninas), com o objetivo de criar soluções tecnológicas para problemas reais da comunidade. Antes e depois das dinâmicas, serão aplicados questionários para avaliar o nível de entendimento sobre o conteúdo abordado, autoavaliação sobre o domínio no assunto e a capacidade de explicá-lo à outras pessoas.

\section{Resultados Preliminares}

Com base nos estudos realizados, experiência das ações das Manas Digitais, e no contexto de distanciamento social causado pela pandemia do COVID-19, o template do primeiro módulo de MDD ("Computação Desplugada") foi produzido pelas alunas de graduação vinculadas ao projeto e revisado pelas educadoras que também fazem parte do projeto. Esse módulo possui inspiração nas atividades apresentadas no site Code.org (https://code.org).

A introdução ao conteúdo, na versão do docente (Figura 5) - chamada de "como abordar o conteúdo" - contextualiza a tecnologia atualmente, onde sua importância está além de apenas usufruí-la e que, nesse contexto, o pensamento computacional 
e seus conceitos surgem como ótimos mecanismos de ensino-aprendizagem. Além disso, descreve quais as vantagens que o ensino da programação pode trazer para os alunos e que esse aprendizado está diretamente ligado com o pensamento computacional, ou seja, quando desenvolvemos habilidades que permitem a resolução de problemas de forma clara, objetiva e eficiente. A Computação Desplugada é mostrada como uma maneira perfeita de introdução ao mundo da computação, e os conceitos de Pensamento Computacional também são detalhados como conceitos necessários para ministrar o conteúdo.

A versão do aluno (Figura 5) é semelhante, porém a contextualização baseia-se em exemplos - como a programação está presente em jogos de videogame - e em como o pensamento computacional pode nos proporcionar diversos benefícios. A Computação Desplugada é mostrada como um dos diversos meios de se aprender programação, e os conceitos de Pensamento Computacional são listados como habilidades que serão desenvolvidas ao longo das atividades.

Figura 5 - Introdução ao Conteúdo (Versão Docente e Aluno).
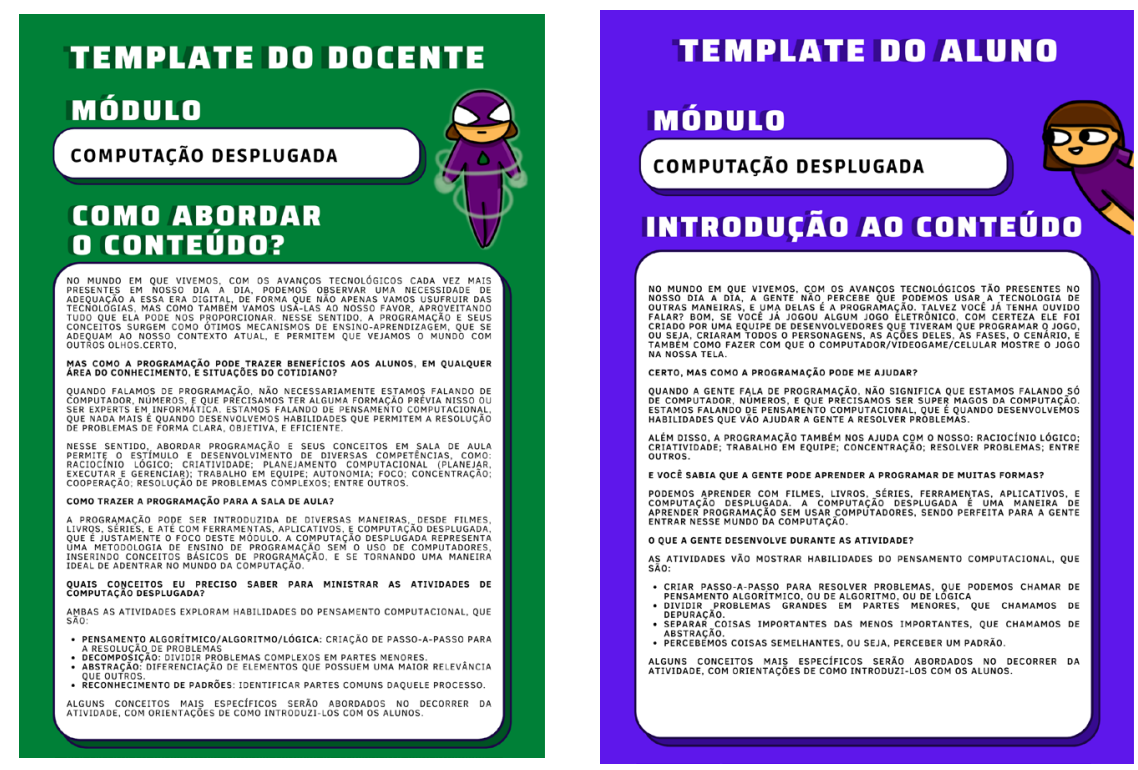

Fonte: Elaborado pelas autoras.

A primeira atividade chamada de "Labirintos com Blocos de Comandos" consiste na criação de um caminho - de acordo com a lógica que será desenvolvida pelo aluno para que alcance um objetivo. São apresentadas as setas de comando (direita, esquerda, cima, baixo e de repetição) e dois labirinto com ordem crescente de dificuldade. $\mathrm{Na}$ versão do professor (Figura 6), o tópico inicia-se com as especificações da atividade, como quais materiais necessários, público-alvo e quais habilidades serão estimuladas. Além disso, explica-se qual o momento ideal para a introdução de alguns conceitos de programação, como algoritmo e looping. 
Figura 6 - Atividade I (Versão Docente).
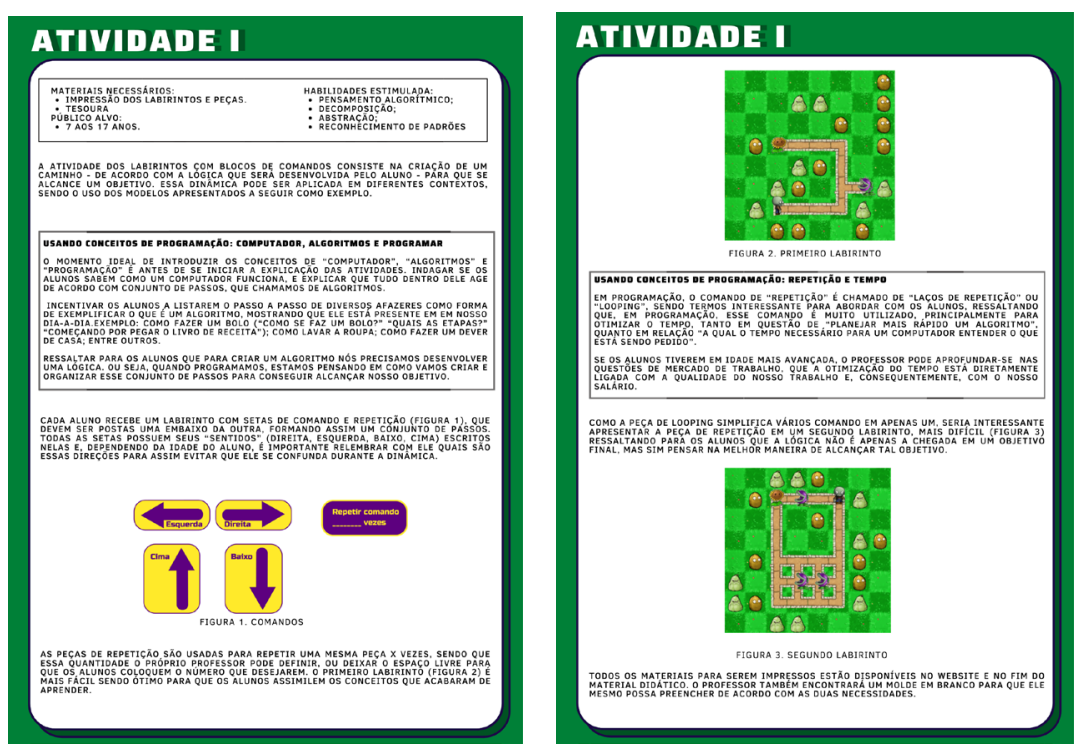

Fonte: Elaborado pelas autoras.

Na versão do aluno (Figura 7), a primeira atividade mantém a mesma estrutura, mas apresenta os conceitos de programação nos momentos que foram indicados na versão do professor. Além disso, apresenta exemplos simples de como utilizar as setas de comando para os alunos de acordo com o jogo de tabuleiro proposto.

Figura 7- Atividade I (Versão Aluno)
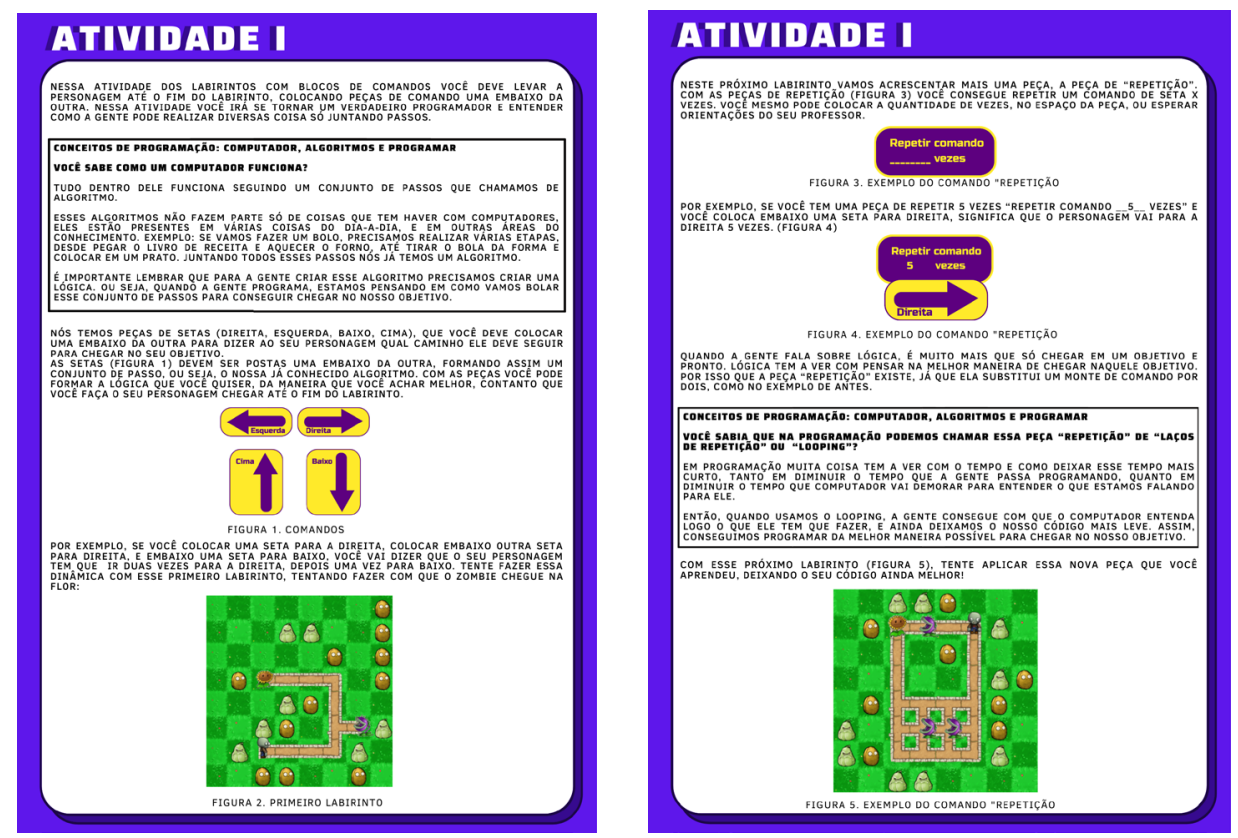

Fonte: Elaborado pelas autoras.

A segunda atividade (Figura 8), chamada e "Labirinto Humano" consiste em um labirinto de tamanho real, feito com fitas adesivas coloridas, onde temos um aluno vendado (que será o computador) que, a partir de uma carta objetivo sorteada, deve ser guiado por um aluno (programador) até que chegue ao final do labirinto. As ações são diferenciadas pela cor da fita que foi colada e os cartões objetivo nos dizem quantas bolinhas (impressas cortadas em papel cartão) nós temos que pegar ao longo

Revista de Estudos e Pesquisas sobre Ensino Tecnológico, v.6, Edição Especial Desafios e avanços educacionais em tempos da COVID-19, 155920, 2020. 
do percurso. Tanto a versão do professor quanto a do aluno seguem a mesma organização da atividade anterior, com orientações e apresentando os conceitos de programação já definidos.

Como finalização do módulo (Figura 9), a versão do professor apresenta, na sessão de "dicas", pontos como: materiais que podem substituir os que foram listados nas atividades (fitas adesivas coloridas, cartões objetivo, impressão do material); como otimizar o tempo da atividade; como se preparar para situação de falta ou ganho de tempo; separação do material entre os alunos; se a atividade é ideal ou não para ser feita em grupo; entre outros. Além disso, na sessão de "Outras Dinâmicas", exemplos rápidos de como a Computação Desplugada pode ser usada em outras áreas do conhecimento, como: labirinto de formar palavras; de juntar molécula; de desafios com fórmulas matemáticas; de países e estados; entre outros.

Figura 8 - Atividade II (Versão Docente e Aluno).
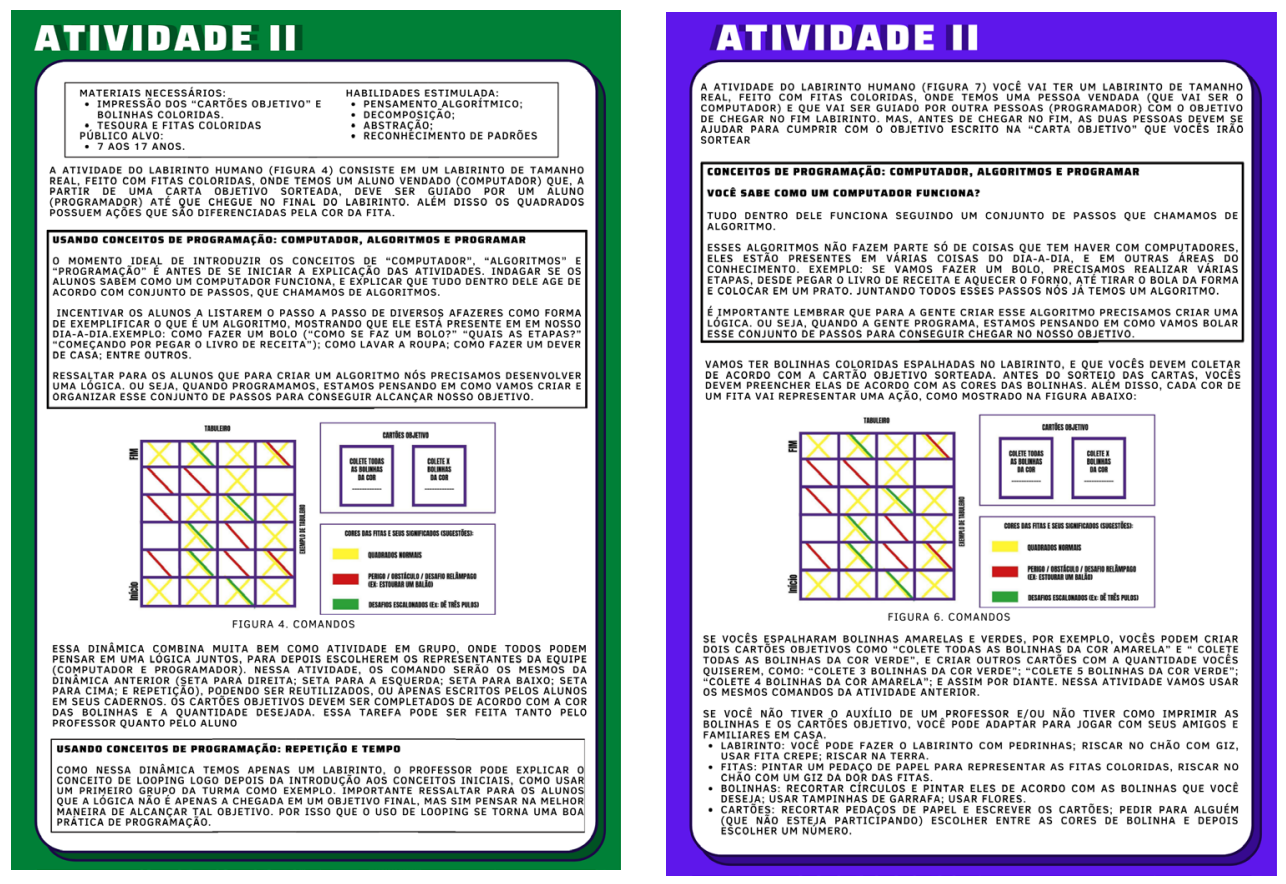

Fonte: Elaborado pelas autoras.

$\mathrm{Na}$ versão do aluno, a sessão de "Reflexões" apresenta as ideias principais apresentadas nas atividades, como a interdisciplinaridade da programação, e a importância da lógica em nossas atividades. Já a sessão "personalidade" apresenta a história de Ada Lovelace, matemática e escritora inglesa, conhecida por ter sido a primeira programadora do mundo, ao criar, pela primeira vez, um algoritmo para ser processado por uma máquina. Ada representa ainda hoje a luta pela permanência de mulheres na tecnologia e na matemática. 
Figura 9 - Conclusão do MDD (Versão Docente e Aluno).
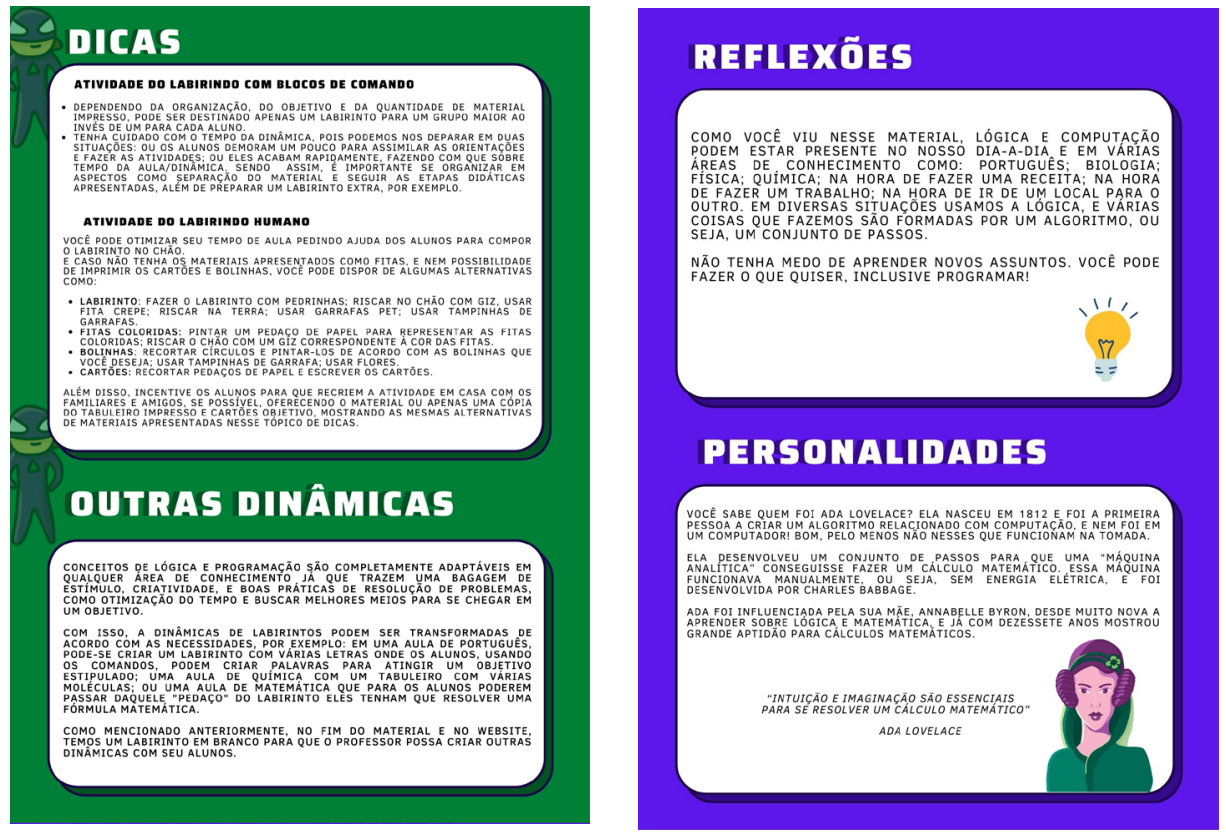

Fonte: Elaborado pelas autoras.

\section{Considerações Finais}

Desde que a pandemia do COVID-19 se instalou no mundo, bilhões de estudantes ficaram fora da escola, no Brasil, por enquanto, a maior parte dos governos estaduais e municipais tem optado pelo fechamento total para reduzir as chances de que os estudantes se tornem vetores do vírus para suas famílias.

A substituição de aulas presenciais por aulas a distância evidenciou a desigualdade de acesso às ferramentas de aprendizagem virtual, além de diferenças significativas de conectividade entre as regiões brasileiras, bem como o meio rural e urbano. Esta assimetria também pode ser observada entre escolas privadas e públicas, principalmente no Norte do Brasil.

A partir das necessidades de ensino-aprendizagem pontuadas, este trabalho em processo de desenvolvimento, tem como objetivo principal a criação de um MDD inovador que possa se tornar material de referência em Pensamento Computacional para Escolas Públicas, além de se tornar modelo para preparação de material em diversas disciplinas auxiliando professores no Ensino Remoto ou EAD.

O trabalho está produzindo templates, modelos e protótipos relacionados ao MDD para Programação que será disponibilizado gratuitamente - através de um website a partir de técnicas relativas ao uso de Design Educacional. A fim de diminuir o abismo socioeconômico do aprendizado em EAD, oferecendo um MDD acessível, inovador e de qualidade tanto como material impresso quanto para ser acessado através de computadores ou aplicativos móveis. Enfatizando também que áreas como STEM são ambientes para todos, principalmente meninas e mulheres, já que muitas vezes materiais didáticos escolares dão mais ênfase a homens inventores e cientistas, tornando assim a presença de mulheres nestas áreas quase "invisível" aos alunos do Ensino Fundamental e Médio.

Revista de Estudos e Pesquisas sobre Ensino Tecnológico, v.6, Edição Especial Desafios e avanços educacionais em tempos da COVID-19, 155920, 2020. 
O cenário de pandemia gerou instabilidade, mas também oportunidades de aprendizado. Mesmo quando o foco está em medidas emergenciais, é importante iniciar o desenho de ações pós-pandemia para mitigar possíveis desigualdades sociais e de aprendizado geradas pelo confinamento. Desta forma, utilizando o Design Educacional como ferramenta durante o processo de construção do MDD para Ensino de Pensamento Computacional, as Manas Digitais pretendem contribuir com educadores e Escolas Públicas e auxiliar o processo de ensino e aprendizagem, a partir de templates que poderão servir de modelos para os milhares de professores que neste momento precisam se adaptar e reinventa-se.

Além disso, durante o período de quarentena tanto alunas quanto professoras vinculadas ao projeto Manas Digitais se viram cada vez mais conectadas, como agentes de mídia com ampla capacidade de gerar e compartilhar informações e influenciar a sociedade. Reinventar-se foi imperativo e a tecnologia nos tornou mais "huMANAS" em nossas mensagens e conteúdos.

\section{Referências}

ALMEIDA, Jéssica Souza de. Material didático para o ensino aprendizagem das cinco emoções básicas e desenvolvimento da empatia. 2017. 139 p. Monografia (Graduação em Design Visual), Universidade Federal do Rio Grande do Sul, Porto Alegre, 2017.

BATISTA, Maria Luiza França da Silva. Design Instrucional: uma abordagem do design gráfico para o desenvolvimento de ferramentas de suporte à EAD. 2008. 254 p. Monografia (Mestrado em Design), Universidade Estadual Paulista, Bauru, 2008.

BATES, Anthony. Educar na Era Digital: design, ensino e aprendizagem. Número da edição. São Paulo: Artesanato Educacional, 2016.

BECKER, Jaqueline. Mobile learning como suporte de uma modalidade híbrida na educação corporativa. 2019. 167. Dissertação (Mestrado em Educação e Novas Tecnologias), Centro Universitário Internacional UNINTER, Curitiba, 2019.

BELL, T; WITTEN, I; FELLOWS, M. Computer Science Unplugged (2015). Disponível em: https://classic.csunplugged.org/wpcontent/uploads/2015/01/unplugged-book-v1.pdf. Acesso em 13 out. 2020.

BRASIL. Base Nacional Comum Curricular. Ministério da Educação. Brasília, DF: MEC.

BROWN, Abbie H; GREEN, Thimothy D. The Essentials of Instructional Design. Nova lorque: Routledge, 2016.

FILATRO, Andrea. Como preparar conteúdos para EAD. Número da edição. São Paulo: Saraiva Educação, 2018.

FILATRO, Andrea. Design instrucional na prática. São Paulo: Pearson do Brasil, 2008.

FILATRO, Andrea; CAIRO, Sabrina. Produção de Conteúdos Educacionais. Número da edição. São Paulo: Saraiva, 2017.

FIGUEIREDO, Dennisy Silva de. Design Educacional: criação e implementação de Capacitação Continuada a Distância para Professores da Rede Estadual de Educação

Revista de Estudos e Pesquisas sobre Ensino Tecnológico, v.6, Edição Especial Desafios e avanços educacionais em tempos da COVID-19, 155920, 2020. 
Básica da Paraíba. 2017. 57 p. Monografia (Graduação em Comunicação em Mídias digitais), Universidade Federal da Paraíba, João Pessoa, 2017.

FILHO, Raul Missfeldt. Desenvolvimento de uma Unidade Instrucional para Ensinar o Desenvolvimento de Apps no Ensino Fundamental com o App Inventor. 2019. 186 p. Monografia (Bacharelado em Ciência da Computação), Universidade Federal de Santa Catarina, Florianópolis, 2019.

GRANDISOLI, Edson; JACOBI, Pedro Roberto; MARCHINI, Silvio. Educação e pandemia: desafios e perspectivas. Jornal da USP São Paulo, 12 ago. 2020. Sessão Artigos.

INEP. Censo Escolar. INEP. Disponível em: http://portal.inep.gov.br/web/guest/resultados-e-resumos. Acesso em 15 jul. 2020.

MACIEL, Cristiano; BIM, Sílvia Amélia; FIGUEIREDO, Karen da Silva. Digital girls program: disseminating computer science to girls in Brazil. In: International Workshop on Gender Equality in Software Engineering, 1.,2018, New York Proceedings..., New York: ACM, p. 29-32.

MOORE, Michael G; KEARSLEY, Greg. Educação a distância: uma visão integrada. São Paulo: Cengage Learning, 2007.

PARDIM, Vanessa Itacaramby. Estudo Bibliométrico da Produção Científica Sobre Design Educacional no Brasil. In: CONGRESSO INTERNACIONAL DE EDUCAÇÃO SUPERIOR A DISTÂNCIA, 6., 2018, Natal. Anais..., Natal: UniRede, 2018, p. 1-15.

PEREIRA, Adriana Soares et al. Metodologia de Aprendizagem em EAD. n. 1, Santa Maria: Núcleo de Tecnologia Educacional, 2017.

SILVA, Ana Vitoria de Bacelar Machado et al. Manas Digitais: um relato sobre Ensino de Programação em Escolas Públicas no Estado do Pará. In: CONGRESSO BRASILEIRO DE INFORMÁTICA NA EDUCAÇÃO, 8., 2019, Brasília. Anais..., Brasília: SBC, 2019, p. 1-10.

WING, J. M. Computational Thinking. Comunication of the ACM, v 49, 3, p 33-35, mar 2006.

Recebido: $14 / 11 / 2020$

Aprovado: 09/12/2020

Como citar: SILVA, A. V. B. M.; SILVA, $\quad$ G. R. R.; COUTO, D. C. C. Design

Educacional como Ferramenta no Processo de Construção de Material Didático Digital para Ensino de Pensamento Computacional. Revista de Estudos e Pesquisas sobre Ensino Tecnológico (EDUCITEC), v. 6, Ed. Esp. Desafios e avanços educacionais em tempos da COVID-19, e155920, 2020.

Direito autoral: Este artigo está licenciado sob os termos da Licença Creative CommonsAtribuição 4.0 Internacional.

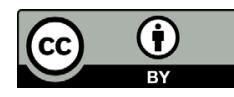

Revista de Estudos e Pesquisas sobre Ensino Tecnológico, v.6, Edição Especial Desafios e avanços educacionais em tempos da COVID-19, 155920, 2020. 